\title{
Homogeneous Development of Electrical Excitability via Heterogeneous Ion Channel Expression
}

\author{
Angeles B. Ribera \\ Department of Physiology, University of Colorado Health Sciences Center, Denver, Colorado 80262
}

Synchronous differentiation of delayed-rectifier potassium current regulates electrical excitability and calcium entry in motor, sensory, and interneurons of the developing amphibian spinal cord. Although Kv1 and Kv2 potassium channel transcripts are detectable in these cells, it is not known which transcript contributes to functional expression. Overexpression of a Kv1 dominant-negative subunit indicates that $20 \%$ of neurons have only Kv1 potassium currents. In other neurons, non-Kv1 channels function because the dominant-negative subunit either only partially suppresses or has no effect on current. Thus, diverse embryonic neurons coordinate differentiation of excit ability yet rely on heterogeneous potassium channel gene expression.

Key words: potassium channels; Xenopus embryos; electrical excitability; neuronal differentiation; gene expression; dominant negative
The delayed-rectifier potassium current $\left(I_{\mathrm{KV}}\right)$ plays a pivotal role in maturation of the action potential (Barish, 1986; O'Dowd et al., 1988; Lockery and Spitzer, 1992; Ribera and Spitzer, 1992). $I_{\mathrm{KV}}$ is initially small when impulses are of long duration. Uniform increases in the $I_{\mathrm{KV}}$ density of all primary spinal neurons synchronize conversion of long-duration calcium-dependent action potentials to brief sodium-dependent spikes.

By regulating the duration of the action potential, $I_{\mathrm{Kv}}$ also determines the amount of calcium influx associated with impulse generation. In amphibian spinal neurons, spontaneous calcium transients associated with long-duration action potentials provide developmental cues necessary for development of neurotransmitter expression and potassium channel kinetics (Gu and Spitzer, 1995). Thus, mechanisms that regulate $I_{\mathrm{K} v}$ will have an impact on neuronal differentiation (Jones and Ribera, 1994).

Potassium channels are thought to consist of four pore-forming $\alpha$ subunits (MacKinnon, 1991; Liman et al., 1992) as well as auxiliary cytoplasmic $\beta$ subunits (Rettig et al., 1994). Four major subfamilies of potassium channel $\alpha$ subunits have been identified: Kv1, Kv2, Kv3, and Kv4 (Chandy, 1991; Salkoff et al., 1992). Within each subfamily, several variants may exist and coassemble to form heteromeric channels. However, coassembly of subunits from different subfamilies (e.g., Kv1.1 and Kv2.2) has not been observed.

Developmental regulation of $I_{\mathrm{Kv}}$ may be under direct transcriptional control, because a critical period of RNA synthesis has been associated with maturation of $I_{\mathrm{Kv}}$ in all embryonic spinal neurons (Ribera and Spitzer, 1989). Candidate, relevant potassium channel $\alpha$ subunit genes are Xenopus Kv1.1 and Kv2.2, which are

\footnotetext{
Received Aug. 18, 1995; revised Oct. 20, 1995; accepted Oct. 27, 1995.

This work was supported by National Institutes of Health Grants RO1-NS25217 and KO4-NS01531. I thank the following people: A. Hofmann for excellent technical assistance; L. Blair, D. Gurantz, R. Levinson, B. Sather, N. Spitzer, and the members of my laboratory for discussions; and T. Finger for generation of the digital composite of Figure 4 . The CS2+MT vector was generously given by D. Turner. D. Gurantz developed and shared computer programs for the analysis of whole-cell currents.

Correspondence should be addressed to Angeles B. Ribera, Department of Physiology, C-240), University of Colorado Health Sciences Center, Denver, CO 80262. Copyright 01996 Society for Neuroscience 0270-6474/96/161123-08\$05.00/0
}

expressed in embryonic spinal neurons and induce expression of delayed-rectifier channels in heterologous systems (Ribera and Nguyen, 1993; Burger and Ribera, 1996). Early overexpression of Kv1.1 potassium channel RNA in Xenopus embryos leads to premature increase in the density of $I_{\mathrm{Kv}}$ in all primary spinal neurons (Jones and Ribera, 1994).

Although previous studies are consistent with the hypothesis that Kv1.1 expression underlies the endogenous delayed-rectifier current, the presence of mRNA does not demonstrate conclusively either the synthesis or the activity of the resultant protein. Additionally, functional overexpression of cxogenous RNA is possible regardless of the nnolecular identity of the endogenous current. Thus, overexpression of wild-type functional potassium channel mRNA does not inform about the molecular composition of the native delayed rectifier.

This study tests directly the possibility that Kv1 gene expression underlies endogenous delayed-rectifier function by overexpression of a mutant $\mathrm{Kv} 1$ subunit that is incapable of expressing current. In heterologous expression systems, this mutant demonstrates a dominant-negative phenotype, because it efficiently suppresses function of coexpressed wild-type Kv1 channels. In situ, this dominant-negative subunit leads to an essentially complete suppression of $I_{\mathrm{Kv}}$ in $\sim 20 \%$ of primary spinal neurons when it is overexpressed in the developing embryo. However, other neurons appear to be affected only partially by or to be resistant to overexpression of the mutant subunit. Thus, different neuronal subtypes possess molecularly distinct potassium currents but regulate maturation of excitability in a synchronous manner.

\section{MATERIALS AND METHODS}

RNA synthesis. The entire coding region of the Xenopus Kvl.1 channel gene, flanked with the $5^{\prime}$ - and $3^{\prime}$-untranslated sequences of $\beta$-glohin, was excised from a pSP64'I' construct (Ribera and Nguyen, 1993) and cloned into the pALTER vector (Promega, Madison, WI). The untranslated sequences confer stability and efficient expression on exogenously introduced RNA (Liman et al., 1992). The resulting recombinant pALTER was linearized with $X b a$ l. Capped sense RNA was generated by in vitro transcription with SP6 RNA polymerase (Promega) in the presence of ribonucleoside triphosphates (Pharmacia, Piscataway, $\mathrm{NJ}$ ) and Cap ana$\log$ (Boehringer Mannheim. Indianapolis, IN). RNA concentrations were 
determined spectrophotometrically and confirmed by elcetrophoresis in agarose-formaldehyde gels.

Site-directed mutagenesis. A tryptophan-to-phenylalanine amino acid substitution in the putative pore region was achicved using the pALTER mutagenesis system according to the manufacturer's instructions (Promega). The mutated residue corresponds to $\operatorname{Trp}^{434}$ in the Shaker $B$ sequence studied previously by Perozo et al. (1993); in addition, silent mutations caused the introduction of an MluI site that permitted rapid screening of resultant clones. To verify that results were attributable to the desired mutation, DNA was prepared from three independent clones; sequencing confirmed that the expected mutation was present in each case. All three clones were used for RNA transcription, and identical results were obtained from their respective RNA preparations.

Oocyte injection and recording. Fifty nanoliters of potassium channel RNA solutions (0.05-0.5 mg/ml) containing varying ratios of wild-typc and mutant KvI RNAs were injected into stage VI, defolliculated Xenopus oocytes as described previously (Ribera, 1990; Ribera and Nguyen, 1993). Oocytes were incubated, and the two-electrode voltage-clamp technique (Axoclamp 2A amplifier; Axon Instruments, Foster City, CA) was used to record voltage-activated outward currents induced in the oocytes 2-4 d after injection of RNA.

For the cocxpression expcriments, RNA mixtures were prepared immediately before injection using a $2 \mu$ l Pipetman (Rainin Instruments, Woburn. MA) for accurate measurement of solution volumes. To keep the amount of wild-type RNA constant in the different solutions, wildtype Kv1.1 RNA was diluted $1: 1$ either with RNase-free $\mathrm{H}_{2} \mathrm{O}$ or with solutions containing varying concentrations of mutant Kvl.I RNA. The binomial equation predicts the percent of channels expected for each clatss of multimeric channel (for details, sec Mackinnon, 1991). Assuming that each channel has four $\alpha$ subunits, the fraction of channels $\left(F_{i}\right)$ that are of a particular type, $i$, is calculated using the binomial distribution:

$$
F_{i}=\left(\begin{array}{c}
4 ! \\
(4-i) ! i !
\end{array}\right) F_{\mathrm{WT}}^{(4}{ }^{\prime \prime} F_{\mathrm{MUT}}^{i}
$$

where $F_{W}$ and $F_{\text {Mer }}$ are the fractions of wild-type and mutant subunits. The total current recorded will be the sum of current carried by each conducting species.

This calculation of the amplitude of the expected current involves three standard assumptions: (1) the ratio of the RNAs injected will predict linearlv their resultant protein ratio; (2) the magnitude of induced current will be dose-dependent on the amount of injected RNA; and (3) the mutant and wild-type subunits will assemble equally well as homo- or heteromeric channels. To maximize the validity of the second assumption, the final concentration of all RNAs in the injection solution was kept at $0.05-0.5 \mathrm{mg} / \mathrm{ml}$; in this concentration range, wild-type RNA causes larger currents as the dose of injected RNA increases. The third assumption is reasonable given that the mutation affects only a single anino acid in the putative pore region and that assembly domains have been located elsewhere (Li et al., 1992: Shen et al., 1993: Babila et al., 1994; Hopkins ct al.. 1994; Lee et al., 1994; Shen and Pfaffinger, 1995).

Embno injections. Introduction of RNA into developing embryos was achieved by injection into one side of the animal pole immediately after first cleavage (Jones and Ribera, 1994). Typically, $5 \mathrm{nl}$ of injection solution wals pressure-injected ( $1-3$ psi for $2-3 \mathrm{sec}$ ) using fine-drawn micropipettes $(\sim 10 \mu \mathrm{m}$ tip diameter; Narashige, Sea Cliff, NY). The injection solution contained a lineage tracer $(20-30 \mathrm{mg} / \mathrm{ml}$ rhodamineconjugated dextran; Molecular Probes, Eugene, OR) and the desired RNA ( $80 \mathrm{pg} / \mathrm{nl}$ ). By external morphological criteria, RNA-injected embryos appear to develop normally (Jones and Ribera. 1994).

Cell culture preparation. Embryos were produced by standard in vitro fertilization techniques (Moon and Christian, 1989) and staged according to Nicuwkoop and Faber (1967). Neurula-stage cultures were prepared as described previously (Jones and Ribera, 1994; Jones et al., 1995). Cultures were viewed on a Nikon Diaphot microscope (Nikon, Melville, NY) with phase-contrast optics or rhodamine-epiffuorescent illumination. Neurons were identified based on morphological criteria (O'Dowd et al., 1988). Fach morphologically identified neuron was scored for rhodamine fluorescence. Visualization of the fluoresence did not interfere with cell survival or subseculuent differentiation.

(-mycepitope tagging. Six copies of the c-myc epitope were fused to the $\mathrm{N}$ terminus of the Kvil. sequence by subcloning into the CS2+MT vector (Turner and Weintratub, 1994), which was provided by D. Turner (Fred Hutchinson (ancer Research Center, Seattle, WA); DNA sequencing verified that the Kv1.1 sequence had been inserted in-frame with the c-myc cpitopes. Similar epitope tagging of the wild-type Kvl.1 sequence did not alter the function of expressed channels, as deduced by expression in oocytes. Cultures were prepared as described above, fixed in $1 \%$ paraformaldehyde, incubated for $1 \mathrm{hr}$ with affinity-purified anti-c-myc monoclonal antibody (1:5; Oncogene, Cambridge, MA), washed, and then incubated in affinity-purified fluorescein-conjugated goat anti-mouse antibody (1:100; Boehringer Mannheim) for $45 \mathrm{~min}$; all incubations and washes were performed at room temperature. Immunoreactivity was not observed when the primary antibody was omitted or when mutant Kv1.1 RNA lacking the six N-terminal epitope tags was coinjected with dextran. Cultures were viewed either with phase optics or with epifluorescence using appropriate filters to detect selectively either rhodamine or fluorescein signals and were photographed with TMax 400 film. Negatives were scanned into Photoshop (Adobe Systems, Mountain View, CA), and the negative graininess was reduced by "dust and scratch" and "blur" algorithms; "unsharp mask" was applied to cnhance edges.

Biophysical methods and analyses. Neurons with short processes $(<50$ $\mu \mathrm{M})$ were selected for recording to avoid space-clamp problems. Before recording, neurons were viewed with epifluorescence to identify them as nonfluorescent (dextran-negative) or fluorescent (dextran-positive); cells with faint fluorescence were not used for electrophysiological analysis. The presence of fluorescent dextran does not alter the electrophysiological properties of the cell (Jones and Ribera, 1994). Whole-cell gigohm recording methods were used (Hamill et al., 1981). An Axopatch 1-C amplifier (Axon Instruments) was used in conjunction with a TL-1 data interface (Axon Instruments), pClamp computer programs (Axon Instruments), and a 386 PC clone for acquisition of data. Electrodes were pulled from borosilicate glass (Drummond Scientific, Broomall, PA) and had resistances ranging between 2 and $4 \mathrm{M} \Omega$ when filled with the pipette solution (100 $\mathrm{mm} \mathrm{KCl}, 10 \mathrm{~mm}$ EGTA, and $10 \mathrm{~mm}$ HEPES, pH 7.4). The bath saline consisted of (in $\mathrm{mm}$ ): $\mathrm{NaCl} 80, \mathrm{KCl} 3, \mathrm{MgCl}_{2} 5, \mathrm{CoCl}_{2} 10$, HEPES 5, pH 7.4. Sodium currents were blocked by addition of $10^{-1} \mathrm{M}$ tetrodotoxin (Sigma, St. Louis, MO); calcium currents were avoided by omission of $\mathrm{CaCl}_{2}$ from the saline and addition of $10 \mathrm{mM} \mathrm{CoCl}$. The capacitative transient was nulled electronically before establishing the whole-cell configuration. Membrane potential was held at $-80 \mathrm{mV}$ and stepped to depolarized voltages ranging between -45 and $+105 \mathrm{mV}$ in increments of 5 or $10 \mathrm{mV}$ for $20-200 \mathrm{msec}$. The currents elicited were digitized at $100 \mu$ sec.

Cell capacitance and series resistance were determined from the capacitative current transient recorded after break-in when sampling at 20) $\mu$ sec intervals. The cell capacitance was used to evaluate the membrane surface area $\left(1 \mu \Gamma / \mathrm{cm}^{2}\right)$ for normalization of current amplitude to density. The series resistance value was used to estimate the associated voltage crror. Leak subtraction was accomplished using a modificd $P / 4$ protocol with 11 subpulses (pClamp 5.5, Axon Instruments). Calculations of current densities, series and input resistances, series resistance voltage errors, time-to-half-maximum values or half-maximum current, and cell capacitances were performed using computer programs that were provided by D. Gurantz (University of California-San Diego, La Jolla, CA). Data are presented as mean \pm SEM. The degree of statistical significance between mean values was calculated by an unpaired nonparametric test (Mann-Whitney $U$ test).

\section{RESULTS}

\section{Creation of a dominant-negative potassium channel subunit}

For several multimeric protcins, subunits that are mutated in critical regions prevent activity of the assembled protein in a dominant manner and, therefore, can be used to knock out the functional contribution of endogenous proteins (Herskowitz, 1987). A dominant-negative potassium channel Kvl $\alpha$ subunit would be expected to perturb the function of Kvl channels (Li et al., 1992; Tu et al., 1995) (Fig. 1). Moreover, because subunits of different subfamilies do not coassemble, potassium channels consisting of Kv2, Kv3, or $\mathrm{Kv} 4$ subunits would be resistant to the effects of a Kvl dominantnegative subunit.

When introduced into the fly Kvl gene, a tryptophan $\rightarrow$ phenylalanine mutation in the pore region produces a nonconducting potassium channel that still generates gating currents (Perozo et al., 1993). Mutation of the analogous residue in Xenopus Kvl.1 creates a 
HOMOMULTIMERS
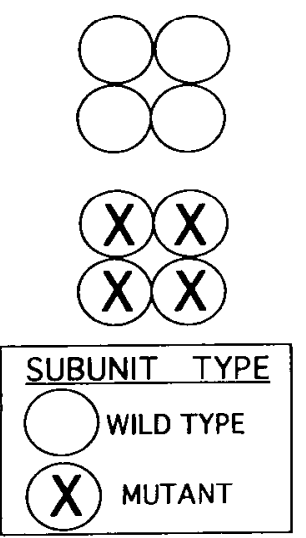

\section{HETEROMULTIMERS}
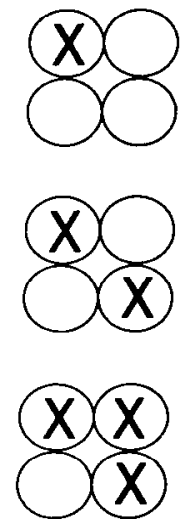

Figure 1. Five different channel types form after coexpression of wildtype and mutant subunits. Two channels are homomultimers of either wild-type $(\bigcirc)$ or mutant $(\otimes)$ subunits. Assuming that potassium channels consist of four porc-forming $\alpha$ subunits (MacKinnon, 1991; Liman et al., 1992), the other three channels are heteromultimers consisting of one, two, or three mutant subunits. A dominant-negative subunit leads to the formation of nonfunctional channels when it coassembles with itself as a homomultimer or with wild-type subunits, leading to heteromeric channels. The only conducting channel species would be the homomultimer of wild-type subunits.

subunit that does not form functional channels when expressed as a homomultimer (Fig. 2A). In addition, inclusion of the mutant RNA in solutions containing wild-type Kvl.1 RNA leads to a reduction in the amplitude of the expressed current. However, the voltagedependent properties of activation of currents recorded from oocytes injected with either wild-type RNA or with mixtures of wild-type and mutant RNAs are similar (Fig. $2 B$ ). These results suggest that the mutant subunit operates in a dominant-negative manner and prevents expression of functional channels.

\section{Potency of the dominant-negative subunit}

Assuming that potassium channel $\alpha$ subunits form tetrameric channels (MacKinnon, 1991; Liman et al., 1992), coexpression of Xenopus wild-type and mutant Kv1.1 RNAs in the heterologous oocyle expression system will lead to the formation of wild-type and mutant homomultimers and three classes of heteromultimers with one, two, or three mutant subunits (Fig. 1). The binomial equation predicts the percent of channels expected for each class of multimeric channel (MacKinnon, 1991) (see equation in Materials and Methods). Under conditions in which the absolute amount (rather than concentration) of wild-type Kv1.1 RNA is kept constant, addition of mutant KvI.I RNA to injection solutions leads to induction of smaller-amplitude potassium currents (Fig. 2A, Table 1). If the mutant subunit were not dominant, only $6.25 \%$ of assembled channels would be expected to be homomultimers of mutant subunits under conditions of $1: 1$ ratio of wildtype to mutant RNA, and the resultant current, therefore, would be almost twice as large (187.5\% of wild-type alone). However, the current amplitude is substantially reduced compared with wild-type alone (Table 1). At several different ratios of wild-type to mutant Kv1.1 RNAs, the magnitude of the reduction in current amplitude is that expected if one or at most two mutant subunits act in a dominant-negative manner to prevent the formation of functional channels (Table 1). (For the purposes of this study, if two- or one-mutant $\alpha$ subunits prevent functional expression of the tetrameric potassium channel, the subunit is considered to be a dominant-negative one.)

Pharmacological tests also assess the potency of the mutant subunit. In heterologous expression systems such as the oocyte, homomultimeric wild-type channels composed of either Kvl.1 or Kv1.2 subunits have different sensitivities to the blocker tetracthylammonium (TEA; Fig. 3): Kv1.1 channels are $50 \%$ blocked by 1 $\mathrm{mm}$ TEA, whereas $150 \mathrm{~mm}$ TEA produces little reduction in current carried by Kv1.2 channels. However, when wild-type Kv1.1 and Kv1.2 mRNAs are coexpressed, the resultant current has an unusually high sensitivity to TEA, given that channels are expected to consist of either homomultimers of Kv1.1 or Kv1.2 or heteromultimers of Kv1.1 and Kv1.2 (Isacoff et al., 1990; McCormack et al., 1990; Ruppersberg et al., 1990; Covarrubias et al., 1991) (Fig. 3). In contrast, under conditions in which wild-type Kv1.2 and mutant Kv1.1 mRNAs are coexpressed, the sensitivity of the small, resultant current to TEA is not distinguishable from that of Kv1.2 homomultimers (Ribera, 1990) (Fig. 3). These results suggest that channels containing a dominant-negative Kv1.1 subunit are nonfunctional and that the only conducting potassium channels are Kv1.2 homomultimers.

Thus, the mutant subunit behaves in a dominant-negative manner. One, or at most two, mutant subunits suffice for functional removal of Kvl channels. On this basis, the mutant Kvl.l subunit should serve as a powerful reagent for knock out of endogenous Kv1 currents.

\section{In situ overexpression of potassium channel subunits}

Microinjection of RNA into cleavage-stage embryos is an efficient method for introduction of exogenous potassium channels into embryonic spinal neurons (Jones and Ribera, 1994). Mutant Kv1.1 RNA was injected under conditions that caused, when used previously for overexpression of wild-type Kvl.1 RNA, a two- to threefold increase in potassium current density. Progeny of the original injected blastomerc are identificd by inclusion of a fluorescent lineage tracer (rhodamine-conjugated dextran) in the injection solution. c-myc epitope tagging of the mutant Kvl.1 sequence assesses the degree of fidelity between the presence of the lineage tracer and protein translated from exogenous RNA. Dextran-positive neurons that meet the criteria for electrophysiological recording are also c-myc-immunoreactive (Fig. 4), demonstrating that the lineage tracer reliably traces the disposition of exogenous protein in neuronal tissue.

\section{Heterogeneous effects of overexpression of a dominant-negative Kv1 subunit}

By $1 \mathrm{~d}$ in culture, the endogenous delayed rectifier has undergone its full extent of maturation and is a large and rapidly activating current (O'Dowd et al., 1988; Ribera and Spitzer, 1989). Neurons derived from uninjected blastomeres exhibit voltage-dependent potassium currents that have densities and kinetic properties expected of the endogenous current (O'Dowd et al., 1988; Ribera and Spitzer, 1989) (Fig. 5). However, fluorescent neurons derived from injected blastomeres often generate small, slowly activating currents (Fig. 5). On average, the dominant-negative subunit leads to both a reduction in density and an increase in the time-to-half-maximum of the delayed-rectifier potassium current of fluorescent neurons (Fig. 6).

Although the average results indicate that the dominantnegative subunit has expected effects in situ, examination of the results from individual fluorescent neurons reveals a surprising degree of heterogeneity, ranging from complete $(n=5 / 25)$ to no 
Figure 2. A single amino acid substitution in the putative pore region of the Xenopus Kvl.1 potassium channel creates a subunit that behaves in a dominant-negative manner. A, Xenopus oocytes were injected with wild-type (top), mutant (middle), or a 1:1 ratio of wild-type to mutant Kv1.1 (bottom) RNAs. Injection of wild-type consistently induces expression of a delayedrectifier potassium current (top), whereas injection of the mutant does not lead to induction of potassium current (middle). Coinjection of wild-type and mutant Kv1.1 RNAs leads to the generation of smaller-amplitude potassium currents (bottom). Scale: $5 \mu \mathrm{A}, 10 \mathrm{msec}$. $B$, The steady-state activation properties of the wild-type current (open squares) and the current remaining after coexpression of wild-type and mutant Kv1.1 RNAs (filled squares) are similar. This result is expected if the mutation either lcads to a dominant-negative subunit or does not interfere with the voltage dependence of activation.
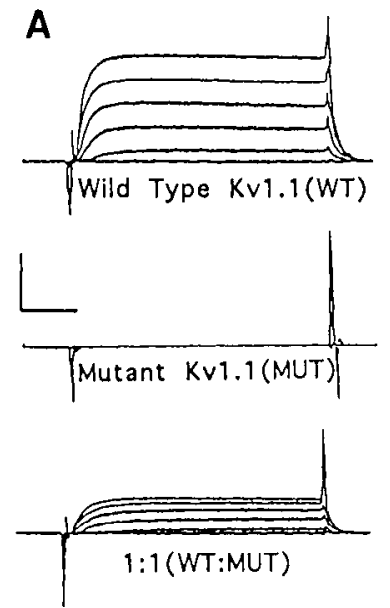

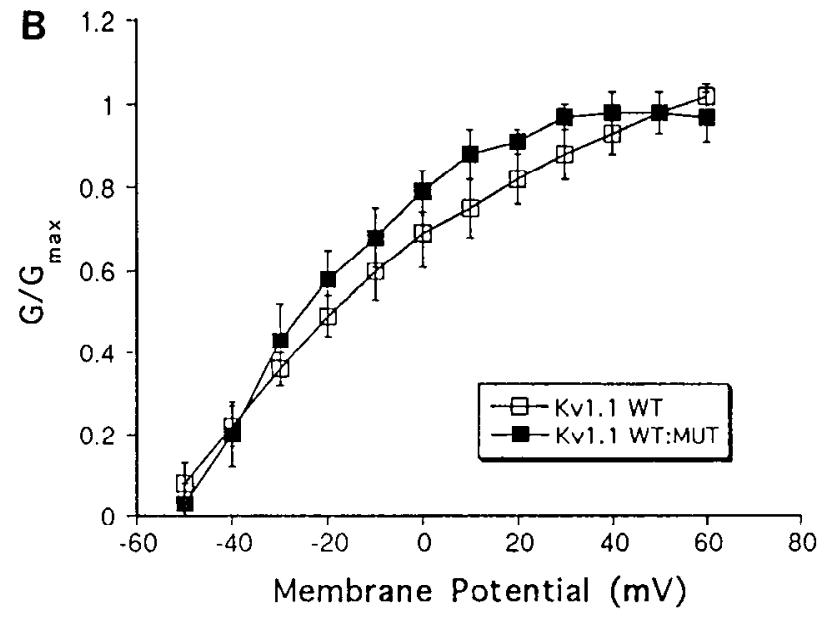

action potential maturation is regulated synchronously by an $I_{\mathrm{Kv}}$ that behaves similarly in all of the neurons (O'Dowd et al., 1988; Ribera and Spitzer, 1992). However, primary spinal neurons are heterogeneous in type (e.g., motor vs sensory) as well as in neurotransmitter sensitivity and content (Bixby and Spitzer, 1984; Spitzer et al., 1993). The present results indicate that heterogeneity is also evident for genes underlying a homologous and synchronized function: $I_{\mathrm{Kv}}$.

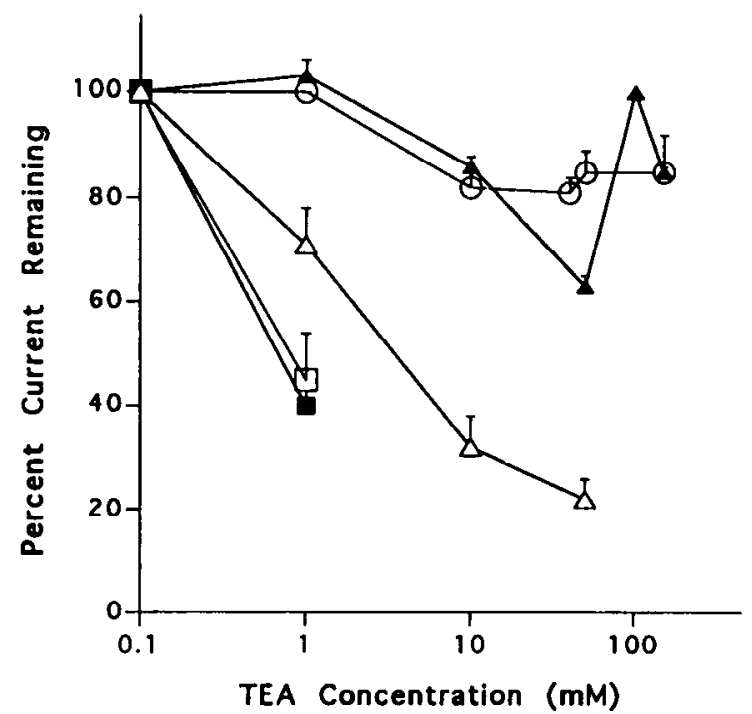

Figure 3. Pharmacological analysis of functional channels formed heterologously in oocytes by coexpression of mutant and wild-type Kvl subunits indicates that the mutant subunit blocks channels in a dominant-negative manner. Coexpression of mutant Kv1.1 with wild-type Kv1.2 (filled triangles) causes the expression of functional channels with sensitivity to TEA that is not different from that obtained by expression of Kv1.2 as a homomultimer (open circles). Open symbols indicate wild-type channels: squares, Kv1.1 homomultimers; circles, Kv1.2 homomultimers; triangles, 1:1 mixtures of Kv1.1 and Kv1.2. Filled symbols represent data from coexpression of mutant Kvl.1 with either wild-type Kvl.1 (squares) or wild-type Kv1.2 (triangles). Values are mean \pm SEM for four to six determinations. 

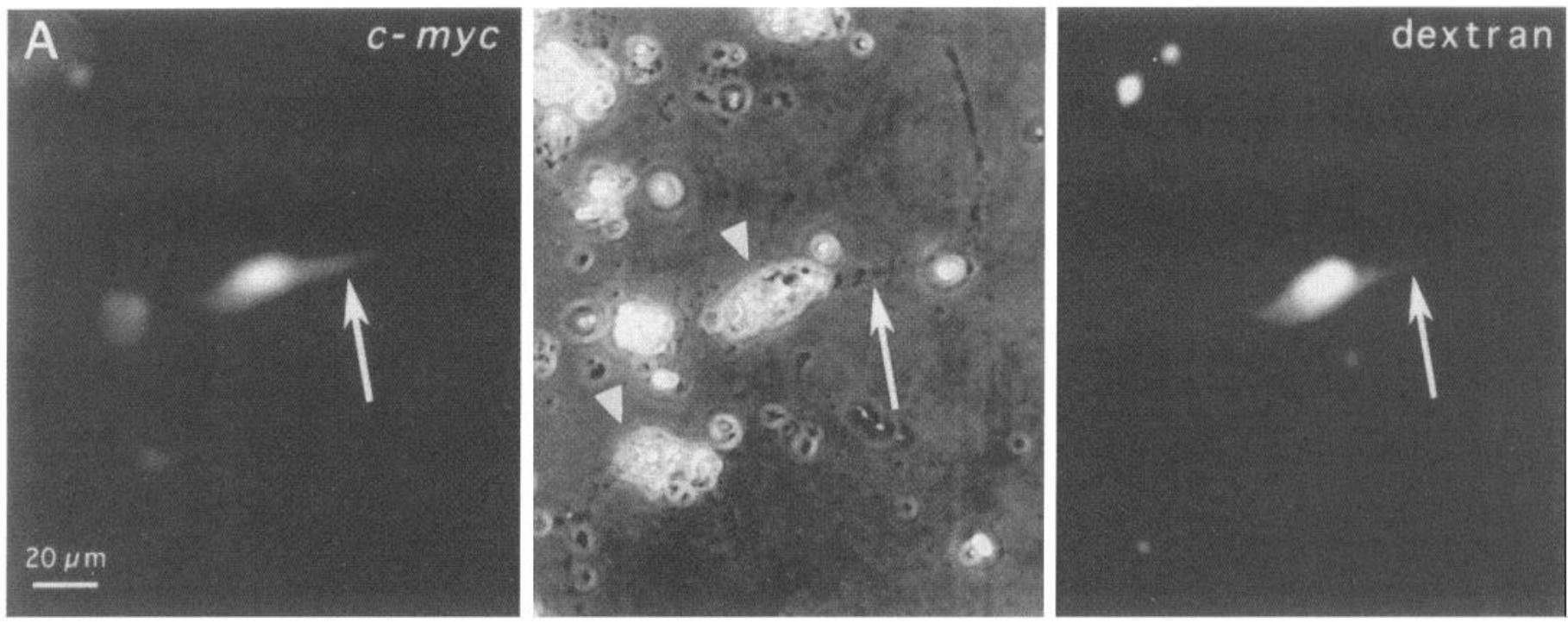

Figure 4. The fluorescent lineage tracer reliably identifies neurons containing protein translated from exogenous c-myc-tagged mutant Kv1.1 RNA. A, Two neurons (arrowheads) in culture are viewed with phase-optics (middle), rhodamine (right), or fluorescein (left) epifluorescence. Rhodamine-conjugated dextran identifies cultured cells derived from the injected blastomere; fluorescein labeling identifies cells that are c-myc-immunoreactive and, thus, express the exogenous mutant Kv1.1 RNA. Yolk platelets and lipid granules are abundant in somata and possess the endogenous autofluorescence that is visualized in the fluorescein channel. Thus, examination of processes (arrows) that do not contain yolk platelets or lipid granules confirms detection of c-myc immunoreactivity. $B$, The percentage of dextran-positive (left) or -negative (right) neurons that are either c-myc-positive (filled bar) or c-myc-negative (open bar) indicates that dextran is a reliable tracer in neurons of protein translated from exogenous RNA; 50 of 57 dextran-positive neurons are also c-myc-positive $(88 \%)$. Conversely, for 186 dextran-negative neurons, 181 were also c-myc-negative $(97 \%)$. Using the selection criterion for electrophysiological analysis of an intense dextran fluorescence (see Materials and Methods), only the 50 c-mycimmunoreactive neurons would have been suitable, indicating that the physiological data appearing in Figures 5-7 are expected to be obtained from the $88 \%$ of neurons that are dextran- and c-myc-positive.

Although the lack of effect of the dominant-negative subunit in some neurons is not accounted for by differential partitioning of the lineage tracer and exogenous RNA (Fig. 4), endogenous potassium channel subunits may escape coassembly with the ex- ogenous dominant-negative subunit if they are not processed cotranslationally or targeted to similar subcellular regions (Sheng et al., 1992; Shen et al., 1993; Deal et al., 1994). However, the fluorescence signal from the epitope-tagged form of the mutant

\section{NONFLUORESCENT NEURONS}

\section{FLUORESCENT NEURONS}

\section{CURRENTS}

Smallest:

Average:
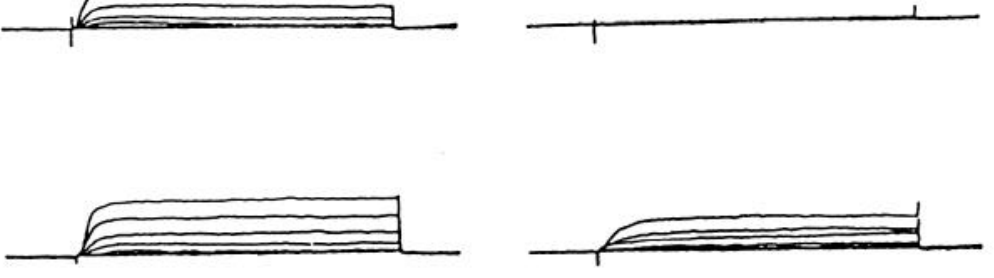

\section{Largest:}
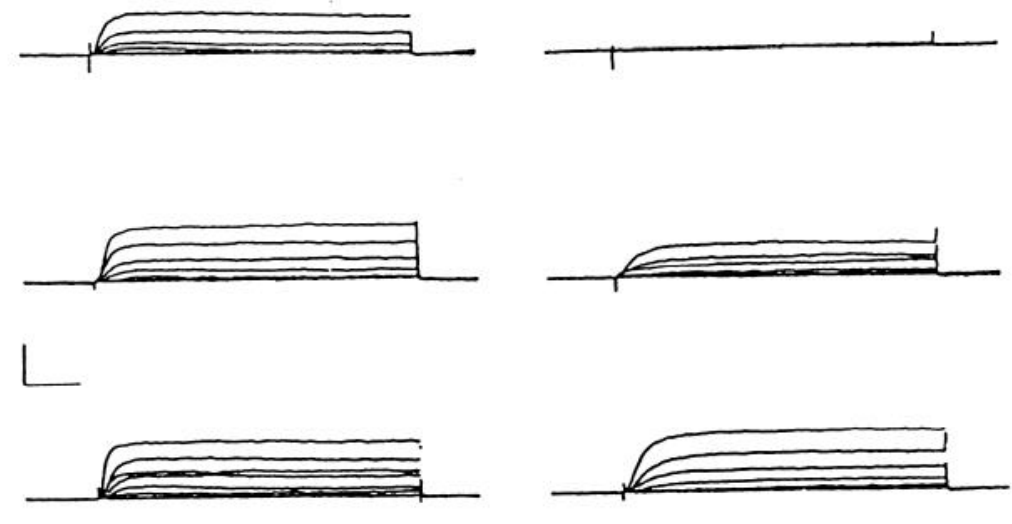

Figure 5. Overexpression of mutant Kv1.1 RNA reduces functional expression of delayed-rectifier potassium current in some, but not all, neurons. Examples of the smallest (top), average size (middle), and largest (bottom) currents recorded from control neurons (nonfluorescent, left) and neurons containing exogenous mutant Kv1.1 (fluorescent, right) are shown. Twenty percent (5/25) of fluorescent cells show complete suppression of current, whereas $20 \%(5 / 25)$ appear to have currents of normal density and activation rate. Scale: $500 \mathrm{pA}, 5$ msec. 

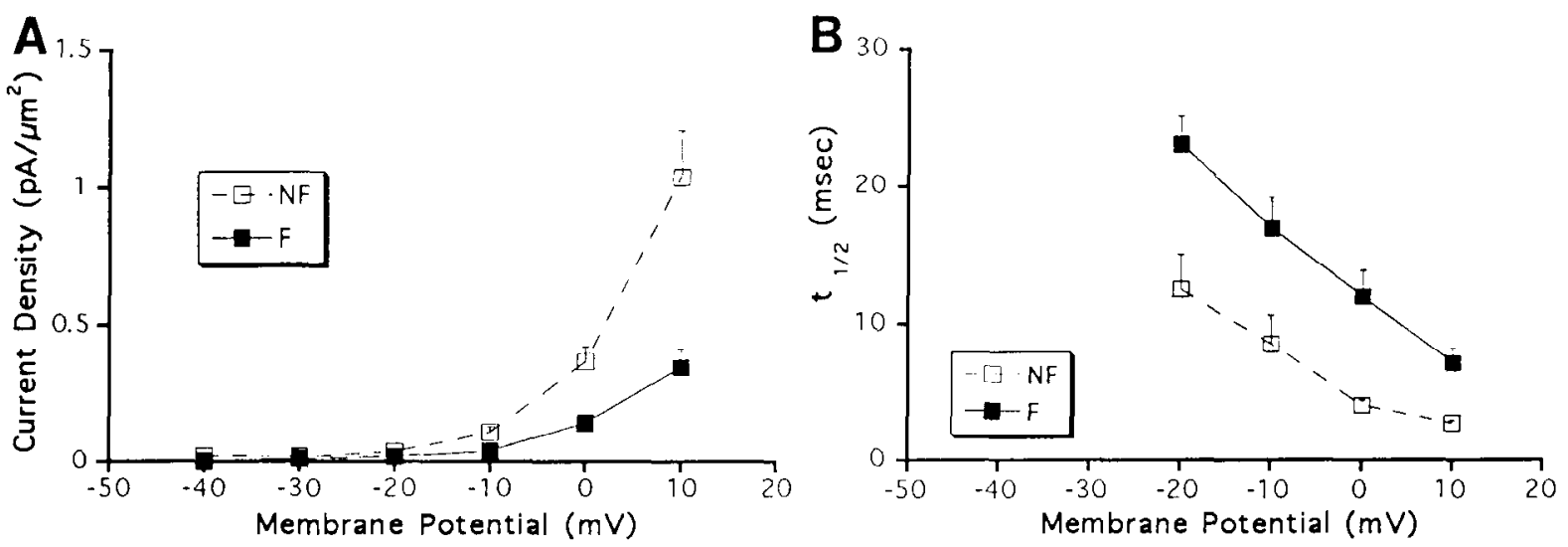

Figure 6. Overexpression of the dominant-negative subunit affects develnpmentally regulated properties of the whole-cell delayed-rectifier potassium current. $A$, Average current density as a function of voltage for fluorescent $(F ; n=25)$ and nonfluorescent $(N F ; n=18)$ neurons. Overall, overexpression of the dominant-negative subunit leads to a reduction in current density. Mean values of $0.4 \pm 0.1 \mathrm{pA} / \mu \mathrm{m}^{2}(n=25)$ and $1.0 \pm 0.2 \mathrm{pA} / \mu \mathrm{m}^{2}(f t=18)$ were obtained for fiuorescent and nonfluorescent neurons, respectively $(p=0.0001)$. $B$, Average time-to-half-maximum as a function of voltage for fluorescent $(F ; n=20)$ and nonfluorescent $(N F ; n=18)$ neurons; fluorescent neurons that had zero-current densities at $+10 \mathrm{mV}$ were excluded. Mean values of 6.1 \pm 1.0 and $2.7 \pm 0.2 \mathrm{msec}$ were obtained for fluorescent and nonfluorescent neurons, respectively $(p=0.001)$. Overall, overexpression of the dominant-negative subunit leads to an increase in the time-to-half-maximum, indicating that currents activate more slowly.
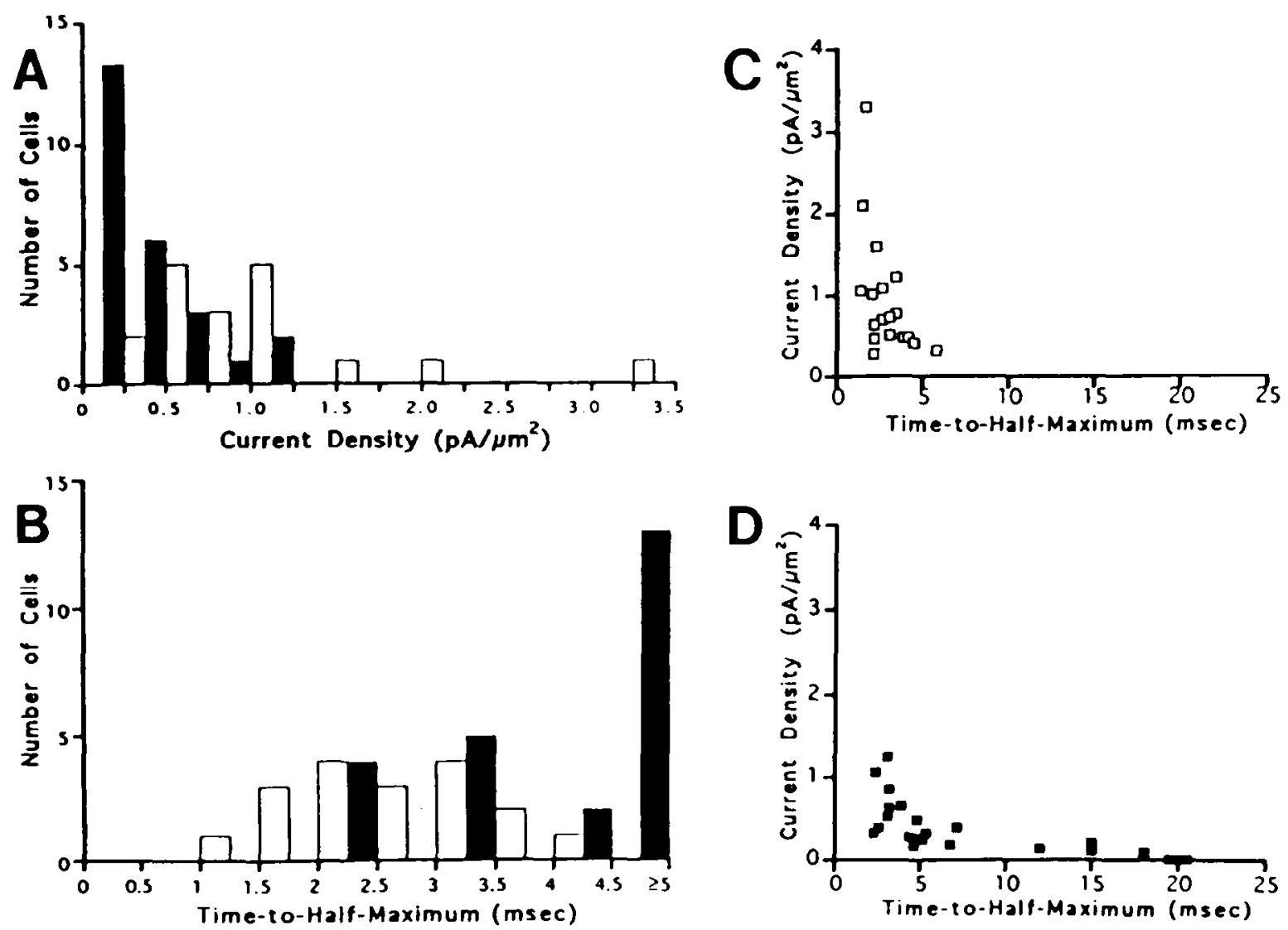

Figure 7. Overexpression of the dominant-negative subunit affects properties of the whole-cell potassium current in some, but not all, neurons. $A$, Histogram of current densities recorded from fluorescent (filled bars) and nonfluorescent (open bars) neurons at $+10 \mathrm{mV}$. The distribution of values for fluorescent neurons is marked by a new population $\left(<0.5 \mathrm{pA} / \mu \mathrm{m}^{2}\right)$ as well as the continued presence of normal values; these results contrast with previous results obtained after overexpression of wild-type Kv1.1 RNA (Jones and Ribera, 1994), for which current densities are shifted uniformly to larger values. $R$. Histogram of time-to-half-maximum values recorded from fluorescent (filled bars) and nonfluorescent (open bars) neurons at $+10 \mathrm{mV}$. After overexpression of mutant Kv1.1 RNA, neurons have cither very large time-to-half-maximum values or values within the normal range. $C, D$, Examination of the correlation between the density and time-to-half-maximum of current recorded from individual fluorescent neurons $(D$, filled symbols, bottom graph) indicates that if a fluorescent cell maintains normal (large) current density, it also has a normal (small) time-to-half-maximum value. This result suggests that overexpression of mutant Kvl.1 either affects both current density and time-to-half-maximum simultaneously or has no effect on either parameter. Values used are those obtained at $+10 \mathrm{mV}$, except for five fluorescent neurons in which current was suppressed completely at $+10 \mathrm{mV}$. Three of these neurons had small, slow currents by activation to potentials between 20 and $30 \mathrm{mV}$. Two additional fluorescent neurons appear in $B$ but not in $D$, because their time-to-half-maximum values were $>20 \mathrm{msec}$, even at activation potentials greater than $+30 \mathrm{mV}$. 
subunit appears throughout the neuron (Fig. 4). Another possible explanation is that native channels assemble before the time of delivery of exogenous mulant RNA and turn over slowly, thus appearing to be resistant to overexpression of a dominantnegative subunit. However, the exogenous RNA is delivered to early two-cell stage embryos, substantially before the time of initial detection of Kv1.1 mRNA in primary neurons (Ribera and Nguyen, 1993).

An intriguing possibility is that the synchronous differentiation of $I_{\mathrm{Kv}}$ is directed by a common $\beta$ subunit. In support of this hypothesis is the recent finding that coexpression of a Drosophila potassium channcl $\beta$ subunit, Hyperkinetic, with $\mathrm{Kvl}$ subunits in a heterologous system leads to the induction of larger, more rapidly activating currents (Chouinard et al., 1995). However, vertebrate potassium channel $\beta$ subunits associate with $\mathrm{Kv} 1$ but not Kv2 subunits (Rhodes et al., 1995), suggesting that a common $\beta$ subunit does not regulate the uniform maturation of $I_{\mathrm{Kv}}$ in diverse neuronal subtypes. In addition, previous work demonstrates that overexpression of $\mathrm{Kvl} \alpha$ subunits suffices for induction of larger potassium currents in embryonic spinal neurons (Jones and Ribera, 1994).

Three considerations strongly support the conclusion that functional expression of more than one potassium channel $\alpha$-subunit gene directs the synchronous developmental regulation of $I_{\mathbf{K v}}$ in Xenopus spinal neurons. First, the experimental paradigm indicates that Kvl channels operate exclusively in at least $20 \%$ of neurons, where they account for the entire voltage-dependent outward current. Similarly, Kvl channels operate in a subset of Drosophila neurons (Baker and Salkoff, 1990). Given that overexpression of wild-type Kvl.l channels causes a uniform two- to threefold increase in current density (Jones and Ribera, 1994), complete suppression of current is consistent with the prediction of the binomial equation ( $\sim 75-95 \%$ reduction; Table 1$)$, assuming that exogenous and endogenous subunits assemble equally well with each other and that all endogenous subunits are of the Kvl subfamily. Second, Kvl channels appear to be either absent or nonfunctional in other neurons that are completely resistant to the dominant-negative Kvl subunit. This is functional confirmation of the molecular heterogeneity that is evident for neural potassium channel gene expression (Drewe et al., 1992; Tsaur et al., 1992; Ribera and Nguyen, 1993; Burger and Ribera, 1996). Third, time-to-half-maximum values of $I_{\mathrm{Kv}}$ in fluorescent neurons that have current densities of normal size fall within the upper range of control (nonfluorescent) values (Fig. 7). This would be expected if non-Kvl channels have slower kinetics of activation than do Kvl channels. In the oocyte, Xenopus Kv2.2 currents activate more slowly than do Kvl.1 currents (Ribera and Nguyen, 1993; Burger and Ribera, 1996). Thus, a strong candidate for another gene encoding endogenous current in spinal neurons is Kv2.2 (Burger and Ribera, 1996). In Drosophila nerve and muscle, Kv2 encodes a majority of their delayed-rectifier currents (Tsunoda and Salkoff, 1995).

In view of the synchronized differentiation of $I_{\mathbf{K}}$ in primary spinal neurons, it is not obvious what advantages are provided by heterogeneous potassium channel gene expression. During the period of action potential differentiation, the primary role of $I_{\mathrm{K} v}$ is action potential repolarization (Barish, 1986; Lockery and Spitzer, 1992). However, the role of this potassium current in controlling impulse frequency has not been examined. At early stages, impulse frequency encodes differentiation cues (Gu and Spitzer, 1995), whereas at later stages it may be critical for establishment of proper functional wiring or plasticity. The dif- ferent biophysical properties of individual potassium channel variants may lead to specific firing patterns, each of which is optimally tuned for a specific neuronal subtype, e.g., motor versus sensory. Thus, in the Xenopus embryo, ion channel genes may serve as sensitive molecular and functional reporters of early aspects of differentiation of excitable tissues.

\section{REFERENCES}

Baker K, Salkoff L (1990) The Drosophila Shaker gene codes for a distinctive $\mathrm{K}^{+}$current in a subset of neurons. Neuron 2:129-140.

Babila T, Muscucci A, Wang H, Weaver FE, Koren G (1994) Assembly of mammalian voltage-gated potassium channels: evidence for an important role of the first transmembranc scgment. Ncuron 12:615-626.

Barish ME (1986) Differentiation of voltage-gated potassium current and modulation of excitability in cultured amphibian spinal neurones. $J$ Physiol (Lond) 375:229-250.

Bixby JL, Spitzer NC (1984) The appearance and development of neurotransmitter sensitivity in Xenopus embryonic spinal neurones in vitro. J Physiol (Lond) 353:143-155.

Burger C, Ribera AB (1996) Xenopus spinal neurons express Kv2 potassium channel transcripts during embryonic development. J Neurosci, in press.

Chandy KG (1991) Simplified gene nomenclature (Abstr). Nature 352:26A.

Christie MJ, North RA, Osborne PB, Douglass J, Adelman JP (1990) Heteropolymeric potassium channels expressed in Xenopus oocytes from cloned subunits. Ncuron 3:405-411.

Chouinard SW, Wilson GF, Schlimgen AK, Ganetzky B (1995) A potassium channel $\beta$ subunit related to the aldo-reductase superfanily is encoded by the Drosophila Hyperkinetic locus. Proc Natl Acad Sci USA 92:6763-6767.

Covarrubias M, Wei AA, Salkoff L (1991) Shaker, Shal, Shab and Shaw express independent $\mathrm{K}^{+}$current systems. Neuron 7:76.3-773.

Deal KK, Lovinger DM, Tamkun MM (1994) The brain Kvl.1 potassium channel: in vitro and in vivo studies on subunit assembly and posttranslational processing. J Neurosci 14:1666-1676.

Drewe JA, Verma S, Frech G, Joho RH (1992) Distinct spatial and temporal expression patterns of $\mathrm{K}^{+}$channel mRNAs from different subfamilies. J Neurosci 12:538-548.

Gu X, Spitzer NC (1995) Distinct aspects of neuronal differentiation encoded by frequency of spontaneous $\mathrm{Ca}^{2+}$ transients. Naturc 375:784-787

Hamill OP, Marty A, Neher E, Sakmann B, Sigworth FJ (1981) Improved patch-clamp techniques for high resolution current recording from cells and cell-free membrane patches. Pflügers Arch 391:85-100.

Herskowitz I (1987) Functional inactivation of genes by dominant negative mutations. Nature 329:219-222.

Hopkins WF, Demas V, Tempel BL (1994) Both N- and C-terminal regions contribute to the assembly and functional expression of homoand heteromultimeric voltage-gated $\mathrm{K}^{+}$channcls. J Neurosci 14:1385-1393.

Isacoff EY, Jan YN, Jan LY (1990) Evidence for the formation of heteromultimeric potassium channels in Xenopus oocytes. Nature $345: 530-534$.

Jones SM, Ribera AB (1994) Overexpression of a potassium channcl gene perturbs neural differentiation. J Neurosci 14:2789-2799.

Lee TE, Philipson LH, Kuznetsov A, Nelson DJ (1994) Structural determinant for assembly of $\mathrm{K}^{\prime}$ channels. Biophys $\mathrm{J}$ 66:667-673.

Li M, Jan YN, Jan LY (1992) Specification of subunit assembly by the hydrophilic amino-terminal domain of the Shaker potassium channel. Science 257:1225-1230.

Liman ER, Tytgat J, Hess P (1992) Subunit stoichiometry of a mammalian $\mathrm{K}^{+}$channel determined by construction of multimeric cDNAs. Neuron 9:861-871.

Lockery SR, Spitzer NC (1992) Reconstruction of action potential development from whole-cell currents of differentiating spinal neurons. J Neurosci 12:2268-2287.

MacKinnon R (1991) Determination of the subunit stoichiometry of a voltage-activated potassium channel. Nature 350:232-235.

McCormack K, Lin W, Iverson LE, Rudy B (1990) Shaker $\mathrm{K}^{+}$channels subunits form heteromultimeric channels with novel functional properties. Biochem Biophys Res Commun 171:1361-1371.

Moon RT, Christian J (1989) Microinjection and expression of synthetic mRNAs in Xenopus cmbryos. Technique 1:76-89. 
Nieuwkoop PD, Faber J (1967) Normal table of Xenopus laevis. Amsterdam: North Holland.

O'Dowd DK, Ribera AB, Spitzer NC (1988) Development of voltagedependent calciun, sodium and potassium currents in Xenopus spinal neurons. J Neurosci 8:792-805.

Perozo E, Mackinnon R, Bezanilla F, Stefani E (1993) Gating currents from a nonconducting mutant reveal open-closed conformations in Shaker K channels. Neuron 11:353-358.

Rettig J, Heinemann SF, Wunder F, Lorra C, Parcej DN, Dolly JO, Pongs $\mathrm{O}$ (1994) Inactivation properties of voltage-gated $\mathrm{K}^{+}$channels altered by the presence of $\beta$-subunit. Nature 369:289-294.

Rhodes KI, Keilgaugh SA, Barrezueta NX, Iopez. KL, Trimmer JS (1995) Association and colocalization of $\mathrm{K}^{+}$channel $\alpha$ - and $\beta$-subunit polypeptides in rat brain. $J$ Neurosci $15: 5360-5371$.

Ribera $\Lambda \mathrm{B}(1990) \wedge$ potassium channel gene is expressed at neural induction. Neuron 5:691-701.

Ribera AB, Nguyen D-A (1993) Primary sensory neurons express a Shaker-like polassium thannel gente. J Neurosci 13:4988-4996.

Ribera AB, Spitzer NC (1989) A critical period of transcription required for differentiation of the action potential of spinal neurons. Neuron 2:1055-1062.

Ribera AB, Spitzer NC (1992) Developmental regulation of potassium channels and the impact on neuronal differentiation. In: Ion channels, Vol 3 (Narahashi T, ed), pp 1-38. New York: Plenum.

Ruppersberg JP, Schroter KH, Sakmann B, Stocker M, Sewing S, Pongs O (1990) Hetero-multimeric channels formed by rat brain potassiumchannel proteins. Nature 345:535-537.
Salkoff L, Baker K, Butler A, Covarrubias M, Pak MD, Wei A (1992) An essential "set" of $\mathrm{K}^{+}$channels conserved in flies, mice and humans. Trends Neurosci 15:161-166.

Shen NV, Pfaffinger PJ (1995) Molecular recognition and assembly sequences involved in the subfamily-specific assembly of voltage-gated $\mathrm{K}$ channel subunit proteins. Neuron 11:67-76.

Shen NV, Chen X, Boyer MM, Pfaffinger PJ (1993) Deletion analysis of $\mathrm{K}^{+}$channel assembly. Neuron 11:67-76.

Sheng M. Tsaur M-L, Jan YN, Jan LY (1992) Subcellular segregation of two A-type $\mathrm{K}^{+}$channel proteins in rat central neurons. Neuron 9:271-284.

Spitzer NC, DeBaca RC, Allen KA, Holliday J (1993) Calcium dependence of differentiation of GABA immunoreactivity in spinal neurons. J Comp Neurol 337:323-333.

Tsaur M-L, Sheng M, Lowenstein DH, Jan YN, Jan LY (1992) Differential expression of $\mathrm{K}^{+}$channel mRNAs in the rat brain and downregulation in the hippocampus following seizures. Neuron $8: 10.55-1067$.

Tsunoda S, Salkoff L (1995) The major delayed rectifier in both Drosophila neurons and muscle is encoded by Shah. J Neurosci 15:5209-5221.

Tu L, Santarelli V, Deutsch C (1995) Truncated K channel DNA sequences specifically suppress lymphocyte $\mathrm{K}^{+}$channel gene cxpression. Biophys J 68:147-156.

Turner DL, Weintraub H (1994) Expression of achate-scute homolog 3 in Xenopus embryos converts ectodermal cells to a neural fate. Genes Dev 8:1434-1447. 